\title{
Using vibration measurements to detect high wear rates in rolling contact fatigue tests
}

\author{
Matteo Lancini ${ }^{1}$, lleana Bodini ${ }^{2}$, David Vetturi ${ }^{1}$, Simone Pasinetti ${ }^{1}$, Angelo Mazzù ${ }^{1}$, Luigi Solazzi ${ }^{1}$, \\ Candida Petrogalli ${ }^{1}$, Michela Faccoli ${ }^{1}$ \\ ${ }^{1}$ University of Brescia, Department of Mechanical and Industrial Engineering, via Branze 38, Brescia, Italy \\ ${ }^{2}$ University of Brescia, Department of Information Engineering, via Branze 38, Brescia, Italy
}

\section{ABSTRACT}

Rolling contact fatigue (RCF) plays a critical role in railway components, and the characterization of materials used, in terms of RCF life, is still an open task, made complex by the interactions of different phenomena. The contact surface has a direct impact on the pressure exerted and can change during the test, due to wear. The procedure proposed consists in using vibrations of a test bench during RCF-life tests to identify when wear increases and causes a quick flattening of the specimen's surface, and when this process is complete. The procedure is applied to two case studies regarding wheel and rail steels. In the tests, a wheel steel specimen rotates against a rail steel specimen, while pressed against each other by a constant force. At regular intervals weight loss and surface analysis are performed, while vibrations and torque are monitored continuously. Destructive tests are carried out at the end of each test. Results from non-destructive measurements were used to provide input data to a numerical simulation, used to determine the cyclic plasticity properties of the material. The methodology proposed shows the potential application of vibration measurements for detecting wear rates thus allowing supporting or partially supplanting destructive testing.

\section{Section: RESEARCH PAPER}

Keywords: damage evaluation; rolling contact fatigue; vibrations

Citation: Matteo Lancini et al, Using vibration measurements to detect high wear rates in rolling contact fatigue tests, Acta IMEKO, vol. 4, no. 4, article 13, December 2015, identifier: IMEKO-ACTA-04 (2015)-04-13

Editor: Paolo Carbone, University of Perugia, Italy

Received December 18, 2014; In final form March 20, 2015; Published December 2015

Copyright: ( 2015 IMEKO. This is an open-access article distributed under the terms of the Creative Commons Attribution 3.0 License, which permits unrestricted use, distribution, and reproduction in any medium, provided the original author and source are credited

Corresponding author: Matteo Lancini, e-mail: matteo.lancini@unibs.it

\section{INTRODUCTION}

Characterization of materials is critical in railway applications because cyclic, localized stresses lead to rolling contact fatigue (RCF) phenomena, which can cause severe damage and sudden failure of components.

Wear, also, is a common phenomenon occurring on both rail and wheels, but its interaction with RCF is not always detrimental: in specific conditions (uniformity, low rate, stability), it could optimize contact geometry, increasing RCF life, while, in non-optimal conditions, it could reduce RCF life.

Moreover, the high shear stress leads to a complex combination of concurring damage phenomena [1], [2] which should be taken into account. Models describing cyclic plasticity are available in literature, but, if material parameters are obtained by laboratory tests in standard stress condition [3], [4], their results are not reliable, especially due to a different propagation mechanism [5].

A reliable procedure to analyze RCF-wear interaction would be to carry on accelerated RCF tests on controlled slip ratio conditions with multiple specimens, interrupting the test at different times and performing destructive analysis on the specimen, which is costly and time consuming.

In this paper, an alternative method is proposed: vibrations and torque are monitored throughout the tests and compared with the damage detected by non-destructive methods (contact surface state, wear) and by destructive methods, at the test end (subsurface microstructure and hardness).

The correlations found between the measured parameters and damage phenomena, occurring at the surface and subsurface region, such as cyclic plasticity or crack nucleation 
and propagation, could be used to replace part of the destructive tests. This would reduce both cost and time needed to perform RCF tests on railway materials.

\section{MATERIALS}

To evaluate the robustness of the proposed approach, different sets of specimens were used. Pairs of discs, machined out of wheel rims and railheads respectively, to represent different materials combinations, made up each set.

A first set, which was called "primary materials", was used to investigate the correlation between results from destructive and non-destructive methods and constitutes the primary experimental data source for this work.

A second set, here called "secondary materials", was used for preliminary tests, performed to select which quantity to monitor, out of the six proposed (see paragraph 3.2).

A third set, moreover, was employed for early stage tests, using the same materials as in the first set, in order to analyze the behavior in the early stages of the process.

\subsection{Primary materials}

The proposed procedure was applied to pairs of wheel rims and railhead materials (ER8 EN13262 and UIC 900A respectively), as a case study, with conditions reported in Table 1 with test id A to F and S3.

The wheel specimens were $60 \mathrm{~mm}$ wide and $10 \mathrm{~mm}$ thick cylindrical discs, while the rail specimens were $59.5 \mathrm{~mm}$ in diameter, $10 \mathrm{~mm}$ in thickness and had a crowning radius of $200 \mathrm{~mm}$, to prevent any border effect on the contact surface.

The mechanical properties of wheel rims (ER8 steel) and railheads (900 A steel) tested, as reported by the manufacturer, are shown in Table 2 .

Three different contact pressure levels were tested, in two different sliding ratio conditions, totaling six different rolling/sliding parameter combinations, here reported in Table 1. Vibration recordings from those with the highest sliding ratio $(\mathrm{s}=3 \%)$ and with the highest nominal pressure $(\mathrm{P}=1500$ $\mathrm{MPa}$ ) were also examined using the proposed procedure.

\subsection{Secondary materials}

A second set of specimen, here called S2, was used in preliminary tests. Sliding ratio, nominal contact pressure and other test condition for this secondary case study are reported in Table 1.

Both wheel and rail specimens had a diameter of $60 \mathrm{~mm}$, and a thickness of $15 \mathrm{~mm}$. Wheels discs were made by machining a SUPERLOS® steel by Lucchini, while rail discs were made by a 900 A steel. Mechanical properties of both materials, as reported by the manufacturer, are listed in Table 2.
Table 2. Material properties of the steels used.

\begin{tabular}{|c|c|c|c|c|}
\hline STEEL & & ER8 & $900 \mathrm{~A}$ & SUPERLOS ${ }^{\circledR}$ \\
\hline Ultimate tensile stress & [MPa] & 940 & 930 & 980 \\
\hline Monotonic yield stress & {$[\mathrm{MPa}]$} & 590 & 470 & 640 \\
\hline Cyclic yield stress & {$[\mathrm{MPa}]$} & 470 & 390 & 525 \\
\hline Necking & {$[\%]$} & 54 & 26 & - \\
\hline Elongation & {$[\%]$} & 17 & 14 & 18 \\
\hline Brinell hardness & {$[\mathrm{HB}]$} & $230-255$ & 296 & 280 \\
\hline
\end{tabular}

\section{METHODS}

\subsection{Measurement system}

The test bench used is a bi-disc machine dedicated to study interactions between two components subjected to cyclic contact in different load conditions, already presented in a previous work by the authors [6], and whose general layout can be found in Figure 1.

The contact load, up to $70 \mathrm{kN}$, is maintained constant by means of a servo-hydraulic actuator, enabling the sliding of one of the mandrels, while two independent $33 \mathrm{~kW}$ engines provide the specimens rotation. Both engines and the actuator are controlled to perform tests at given slip ratio, rotating speed, contact force and engine torque.

On both mandrel supports, piezo-accelerometers were mounted using a cyanoacrylate glue, as shown in Figure 2: one in the vertical and one in the horizontal plane, both normal to the rotation axis. The transducers used were Wilcoxon 736 IEPE accelerometers, with a nominal sensitivity of $0.98 \mathrm{~V} /\left(\mathrm{m} / \mathrm{s}^{2}\right)$, a full scale of $5 \mathrm{~m} / \mathrm{s}^{2}$, and a linear bandwidth in the $5 \mathrm{~Hz}$ to $20 \mathrm{kHz}$ range.

The signals from the two accelerometers, as well as a torque sensor, positioned on the sliding mandrel, were acquired by means of a configurable data acquisition system at a $5 \mathrm{kHz}$ synchronous sampling frequency.

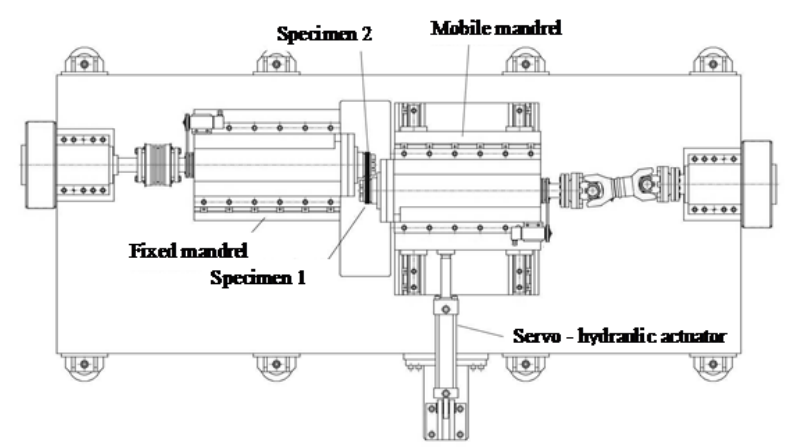

Figure 1. Test bench layout.

Table 1. Test parameters of the first case study (A to F), of the preliminary test (S2) and of the early stage monitoring test (S3).

\begin{tabular}{|c|c|c|c|c|c|}
\hline \multirow[t]{2}{*}{ TEST ID } & $\begin{array}{c}\text { Nominal contact } \\
\text { pressure }\end{array}$ & Contact load & $\begin{array}{l}\text { Rail sample } \\
\text { rolling speed }\end{array}$ & $\begin{array}{l}\text { Wheel sample } \\
\text { rolling speed }\end{array}$ & Sliding ratio \\
\hline & $\mathrm{MPa}$ & $\mathbf{N}$ & r.p.m. & r.p.m. & $\%$ \\
\hline$A$ & 1100 & 1500 & 516.0 & 492.5 & 3 \\
\hline B & 1300 & 2490 & 516.0 & 492.5 & 3 \\
\hline C & 1500 & 3830 & 516.0 & 492.5 & 3 \\
\hline $\mathrm{D}$ & 1500 & 3830 & 511.0 & 497.5 & 1 \\
\hline$E$ & 1300 & 2490 & 511.0 & 497.5 & 1 \\
\hline $\mathrm{F}$ & 1100 & 1500 & 511.0 & 497.5 & 1 \\
\hline S2 & 1100 & 7557 & 497.5 & 502.5 & 1 \\
\hline S3 & 1500 & 3830 & 516.0 & 492.5 & 3 \\
\hline
\end{tabular}




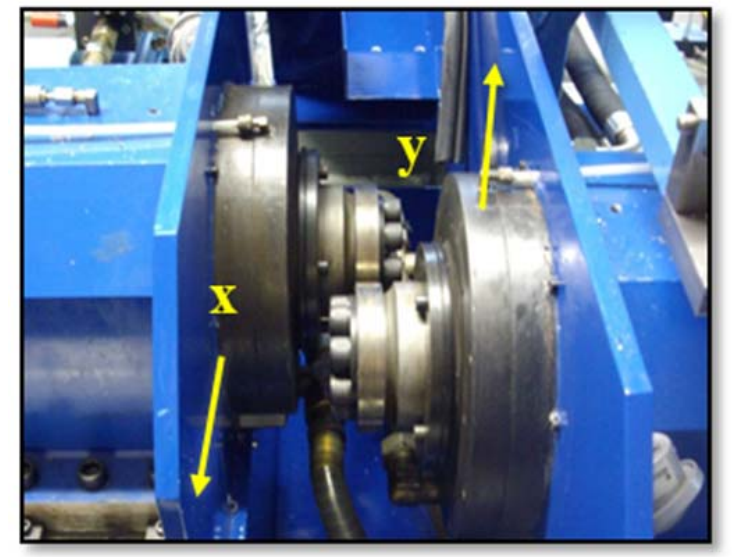

Figure 2. Specimens mounted on mandrels (the accelerometers measuring axes are highlighted).

An L101b-2k BASLER linear array camera was also used to monitor contact surface conditions of both specimens. The camera was acquired in sync with the bench rotation, in a setup leading to a resolution of $1 \mu \mathrm{m}$ on the specimen's mid surface. Due to the high rotation speed, however, it was only used at regular intervals while the test was on halt, and the specimen was moved at $5 \mathrm{rpm}$.

Every $2 \times 10^{5}$ cycles the test was halted and weighing was performed with a precision scale $(0.01 \mathrm{~g}$ resolution), to evaluate weight loss due to wear. At the end of each test, the samples were cut in mid-thickness, polished mechanically and etched (using $2 \% \mathrm{Nital}$ ), then inspected using an optical microscope to measure the plastic flow.

Following this, a LEO EVO-40XVP scanning electron microscope with an EDS probe was used to seek for RCF crack paths, and HV10 micro-hardness was measured at different depths on the cross-section of each sample.

\subsection{Mechanical model}

While vibration analysis is commonly used to detect faults on gears and bearing components [7]-[10], its use in material characterization of continuous discs is limited, as this is usually carried on with standardized methods, generally involving destructive testing or evaluation at the end of test.

In previous works [11] a damage indicator, estimated from vibrations and correlated to surface cracks, was proposed. Following the same approach the two specimens interactions are synthesized, as it is common in modal analysis, using frequency transfer functions (FRF) between torque $T$ and accelerations in the $x$ and $y$ directions, as depicted in Figure 3.

The idea behind this approach is that any variation in the material or geometry of the samples would be reflected by a simultaneous change in the modal parameters of the system, causing a change in the FRFs values. Because of this, a change in the dynamic behavior could be used to assess when crowing gets flattened, and the duration of this wear process.

FRFs were numerically computed as the $H_{a / b}$ cross-spectrum between a signal $a$ and a signal $b$, divided by the auto-spectrum of signal $b$. In particular, the following 6 quantities were monitored:

a. the transmissibility $H_{y / x}$, between the $y$ acceleration on the fixed mandrel support along the vertical axis and the $x$ acceleration of the moving mandrel support along the pneumatic actuator axis,

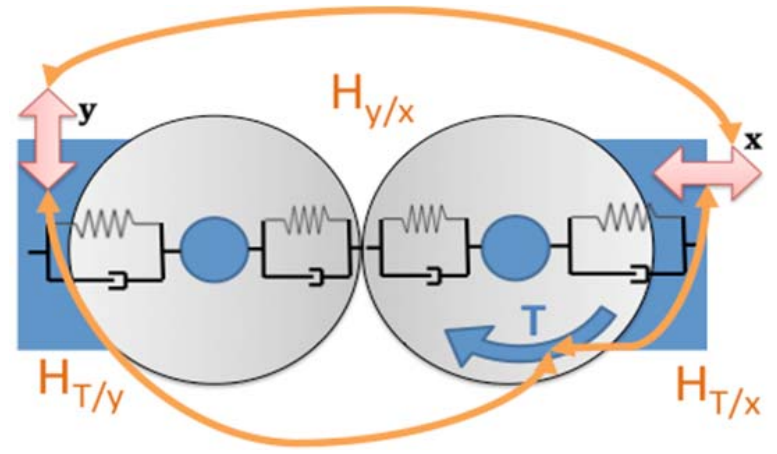

Figure 3. Simplified FRF based model.

b. the rotating inertances $H_{x / T}$ and $H_{y / T}$ between the $x$ and $y$ accelerations and the torque $T$ measured on the rotating axis of the sliding mandrel,

c. the reciprocals to the previous three quantities, $H_{x / y}$, $H_{T / x}$ and $H_{T / y}$.

Though all these quantities are related to properties of the system, such as masses and stiffnesses, their connection to any proper mechanical parameter would require an overly complex multiple degree of freedom model, which would exceed the scope of this research.

Therefore, their absolute values are not meaningful per se, and only their variation from their value at the beginning of each test has been taken into account.

\subsection{Preliminary tests}

Preliminary tests were performed, on the specimens described in Section 2.2, to select which quantity to monitor and in which frequency range.

To avoid misreading due to external or uncorrelated sources of vibrations, the test bench was also monitored while running in jog mode, as well as in full operational mode, but without any load applied between the samples. A power spectral density analysis of $x, y$ and $T$ signals, recorded for about $100 \mathrm{~s}$, and averaged using a $1 \mathrm{~Hz}$ spectral resolution, revealed that their frequency content was located below $400 \mathrm{~Hz}$, while the same analysis performed in the final phases of standardized RCF tests revealed vibrational phenomena up to $1000 \mathrm{~Hz}$.

Moreover, an experimental modal analysis of the pneumatic actuator, pointed out a resonance frequency lower than $100 \mathrm{~Hz}$, therefore, the spectral quantities monitored were treated using a band-pass filter between $400 \mathrm{~Hz}$ and $1000 \mathrm{~Hz}$.

To select which quantity should be monitored, a comparison between the $H$ functions computed, subtracted of their initial value and normalized on their maximum value, was performed during a full test of an unrelated rail/wheel couple, examined in a previous work [11] and here reported in Figure 4.

This comparison pointed out how the FRF between torque and acceleration along the linear actuator axis, here called $T / x$, and its reciprocal $x / T$, displayed a sensible change, coherent with other damage indicators. In the initial 60000 cycles, this quantity is less affected by accidental impacts or other impulsive events, here visible as spikes on the chart, which are frequently occurring due to the uncontrolled environment in which the bench operates.

\subsection{Vibration analysis}

Using the acquired data, the transfer function $H_{T / x}(\omega)$ between torque and acceleration was computed averaging 5 


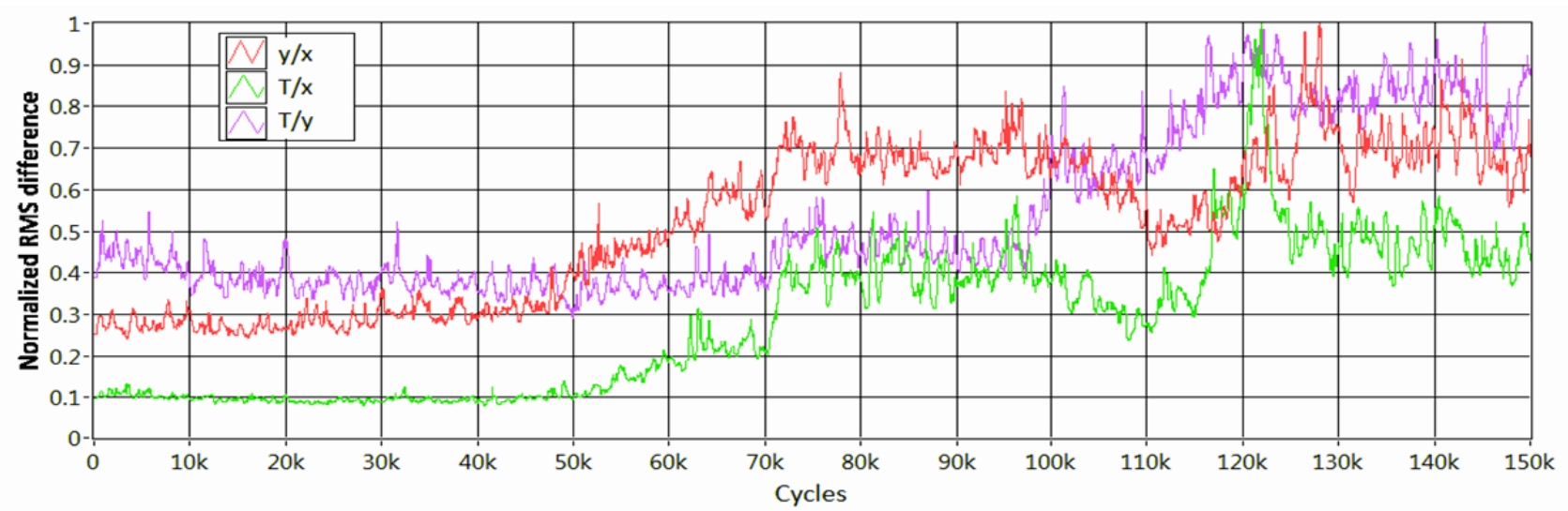

Figure 4. $D_{y / x}, D_{T / x}$ and $D_{T / y}$, on preliminary tests, where wear rate changes were detected by weight loss measurements [11] after 60000 and 100000 cycles.

windows of $1 \mathrm{~s}$, thus producing a spectrum of 1000 lines, with a spectral resolution of $1 \mathrm{~Hz}$, every $5 \mathrm{~s}$.

The initial dynamic behaviour of the system made up by the test bench and the intact specimens were assessed by averaging the $H_{T / y}(\omega)$ values of the first 2500 cycles, thus assumed as a set of reference values $H_{\mathrm{T} / \mathrm{x}}{ }^{\mathrm{ref}}(\omega)$.

To point out changes in the system, the difference $D_{T / x}(\omega)$ between the current status and the reference value, for each frequency resolution $\omega_{i}$, has been computed, then the synthetic index $D_{x / T}$ has been evaluated as the root mean square (RMS) summation for all frequencies, as shown in (1).

$D_{T / x}=\frac{1}{n} \sqrt{\sum_{i=1}^{n}\left(H_{T / x}\left(\omega_{i}\right)-H_{T / x}^{r e f}\left(\omega_{i}\right)\right)\left(H_{T / x}\left(\omega_{i}\right)-H_{T / x}^{r e f}\left(\omega_{i}\right)\right)^{*}}$.

To smooth the resulting signal, given the relative slow damaging process, the RMS value was averaged on a $30 \mathrm{~s}$ window. The same procedure, here illustrated in Figure 5, was performed for the reciprocal $H_{x / T}$, leading to an indicator $D_{x / T}$, which was also monitored during the RCF tests.

\section{RESULTS}

\subsection{Vibrations}

The values of $D_{x / T}$ for the four tests under scrutiny are reported in Figure 6. All three tests with a high sliding ratio

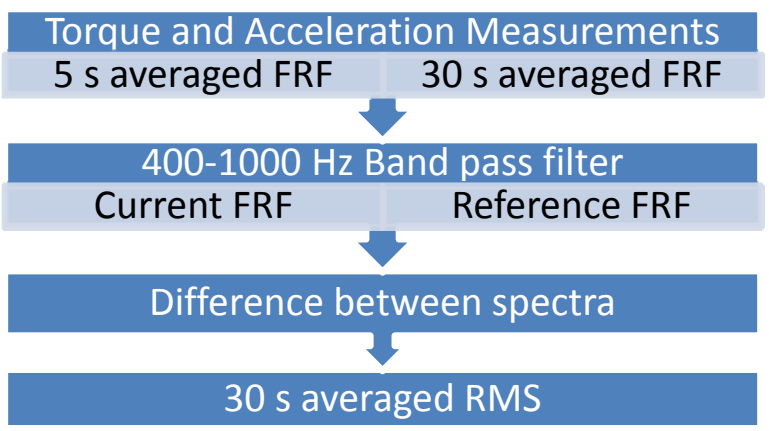

Figure 5. Signal processing procedure's steps.

level $(3 \%)$ report a steep increase in value (from 10 to more than $100 \mathrm{~kg}^{-1} \mathrm{~m}^{-1}$ ), after few thousand cycles, followed by an abrupt decrease after a variable amount of cycles, then settling around a stationary level $\left(30 \mathrm{~kg}^{-1} \mathrm{~m}^{-1}\right)$.

The last test, with a $1 \%$ sliding ratio, displayed only a slight increase after 8000 cycles to a stationary level $\left(20 \mathrm{~kg}^{-1} \mathrm{~m}^{-1}\right)$.

Such behavior could be used to identify a period, characterized by higher $D_{y / T}$ levels, during which the damage process is different from both the initial and the stationary stages. The approximate onset and duration of these periods are reported in Table 3, and their values depend on the nominal contact pressure, as visible in Figure 7.

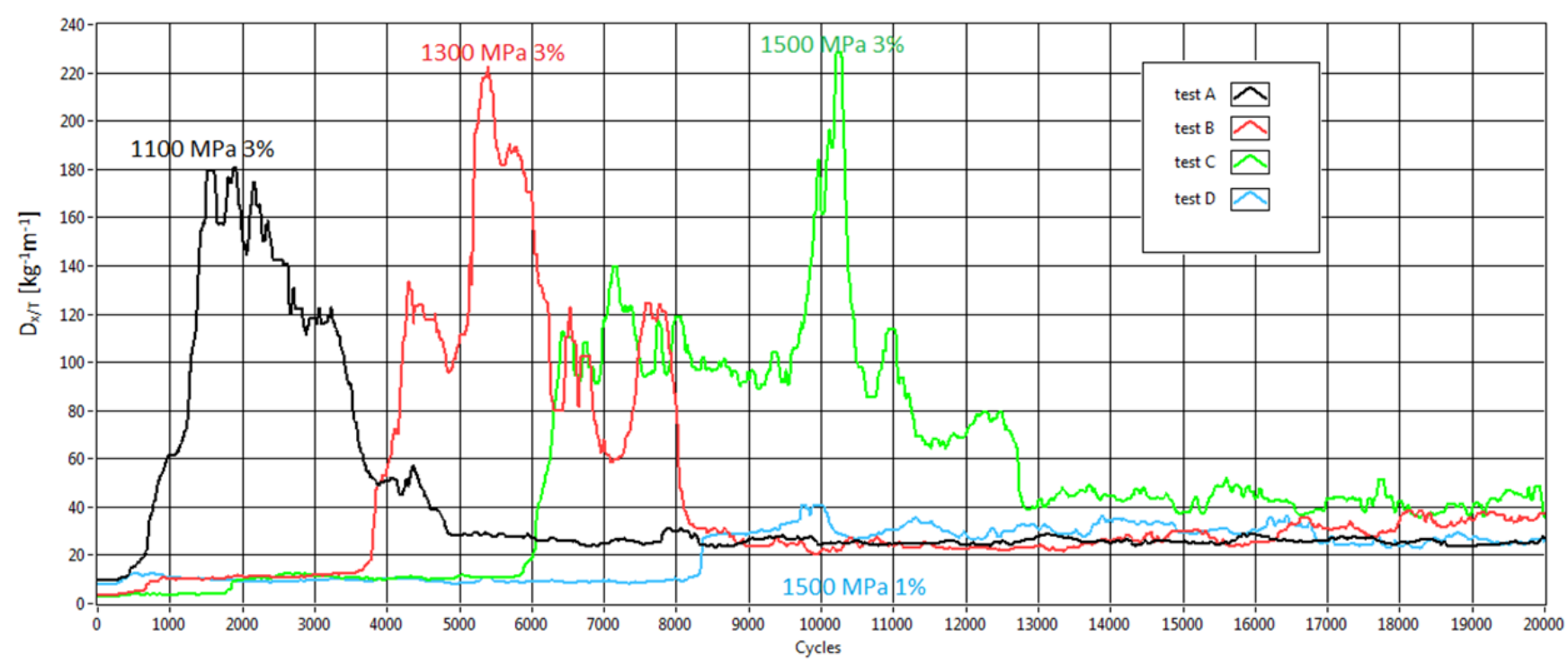

Figure 1. $D_{x / T}$ indicators for tests A (black), B (red), C (green) and D (cyan) during the first 20000 cycles of each test. 
Table 3. Onset and duration of high $\mathrm{D}_{\mathrm{y} / \mathrm{T}}$ levels.

\begin{tabular}{ccccc}
\hline \multirow{2}{*}{ ID } & Onset & Offset & \multicolumn{2}{c}{ Duration } \\
\cline { 2 - 5 } & [cycles] & [cycles] & [cycles] & [s] \\
\hline $\mathrm{A}$ & 700 & 4700 & 4000 & 480 \\
\hline $\mathrm{B}$ & 3800 & 8500 & 4700 & 560 \\
\hline $\mathrm{C}$ & 6000 & 12700 & 6700 & 800 \\
\hline $\mathrm{D}$ & $-n / a-$ & 8200 & $-n / a-$ & $-n / a-$ \\
\hline
\end{tabular}

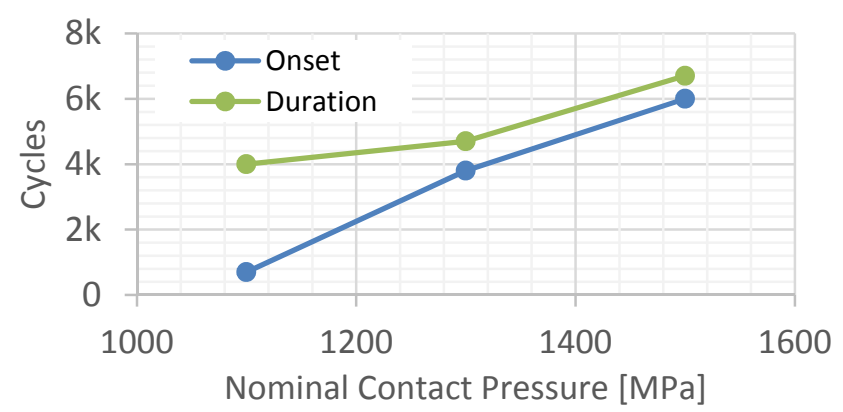

Figure 7. Onset and duration of high $D_{y / T}$ levels.

\subsection{Weight loss}

The wear rate, in terms of weight loss as a function of cycle number, with varying nominal contact pressure $P$, was investigated in tests from $\mathrm{A}$ to $\mathrm{F}$. Results are shown in Figure 8 and Figure 9 for sliding ratios $s=1 \%$ and $s=3 \%$ respectively. Given the linear relationship displayed between weight loss and cycle number in the steady state period of the wear curves, wear rates were calculated as the angular coefficient of the linear best fit of the experimental points.

Wear rate values increased as nominal contact pressure and sliding ratio increased. The wear rate in general was higher for the rail steel samples, despite the surface damage was more severe for the wheel steel specimens: this means that wear, in this case, mitigates the effect of surface pitting by removing damaged layers.

This linear wear rate behavior suggests a stationary contact geometry already achieved before the first measurement (after 200000 cycles), while the difference between $3 \%$ and $1 \%$
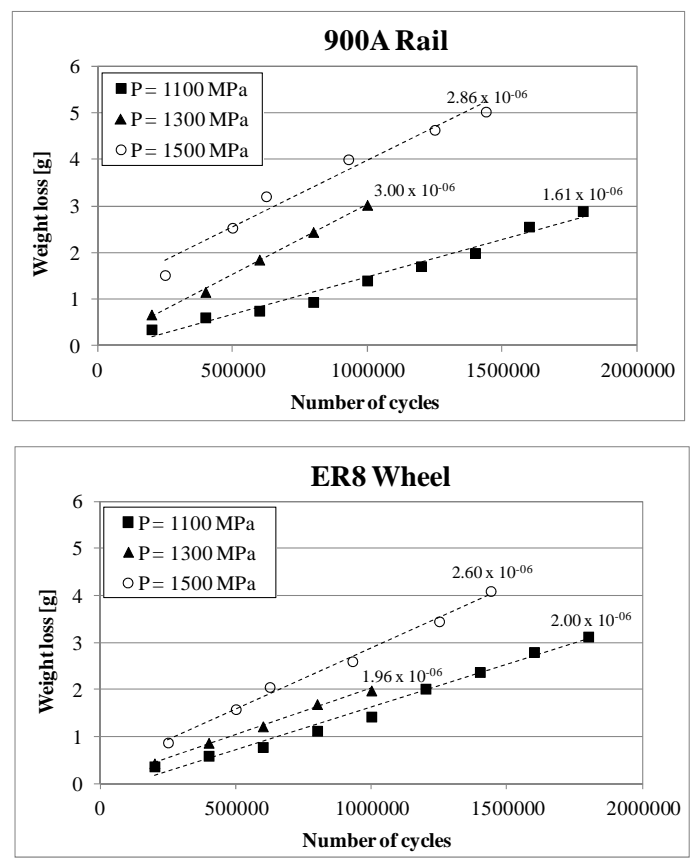

Figure $8.1 \%$ sliding test weight loss for rail (upper) and wheel (lower).

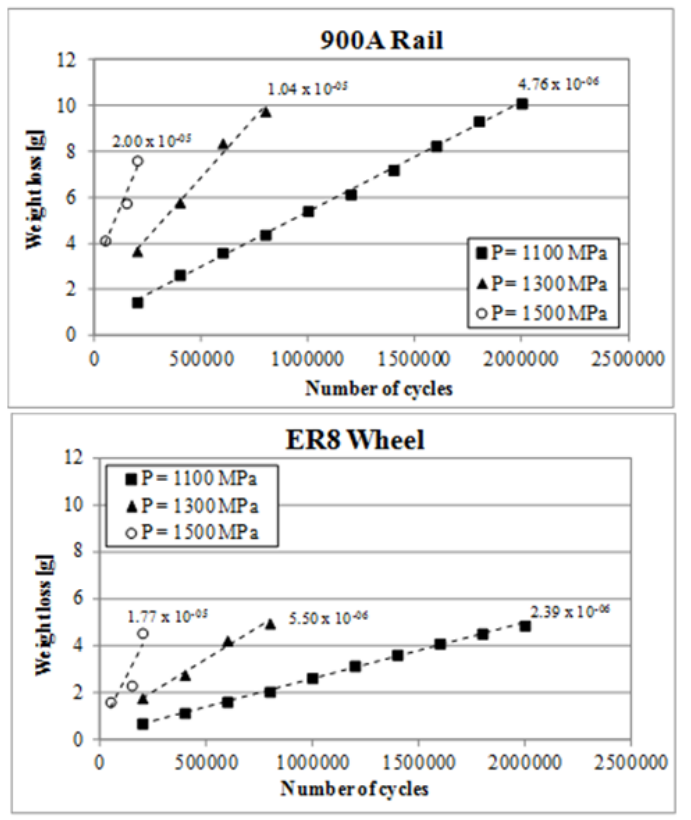

Figure 9. $3 \%$ sliding test weight loss for rail (upper) and wheel (lower).

sliding ratio tests points out a decreased wear rate associated with the lower sliding condition.

\subsection{Damaged surface width}

Shape changes due to wear and RCF were assessed by measuring the worn portion of the wheel specimen as shown on images recorded by the linear camera before test and after 200000 cycles, here displayed in Figure 10 to Figure 13.

The worn portion was identified by visual inspection of the recorded images and by manually selecting the image area of the specimen surface where linear patterns, due to the specimen machining during its production, were not present, or were only partially visible.

The process was repeated on 20 images for each specimen

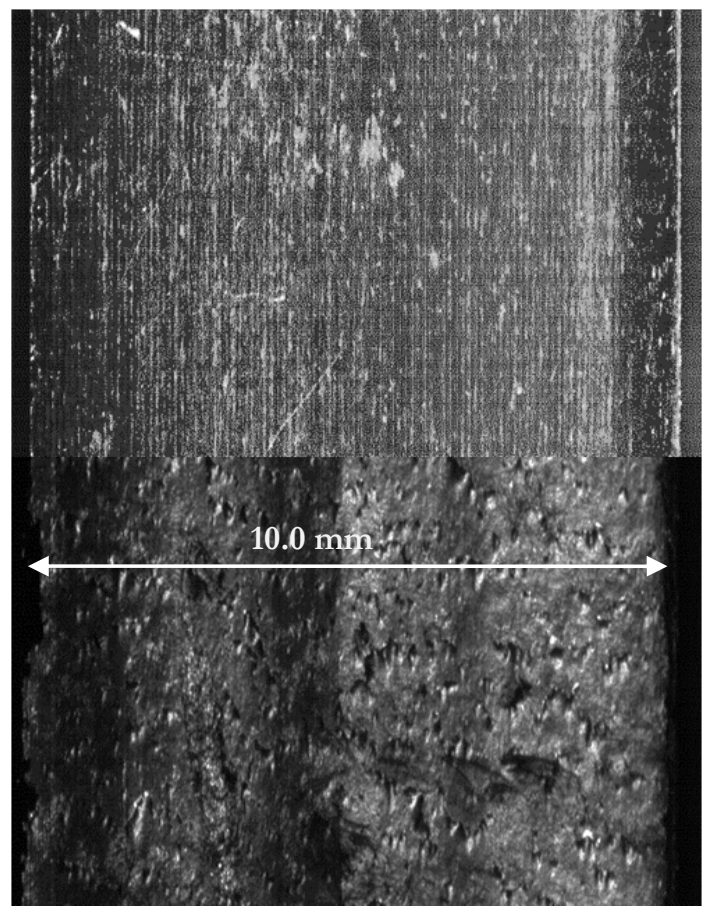

Figure 10. Wheel contact surfaces before (upper) and after (lower) the first 200000 cycles for test $A$. 


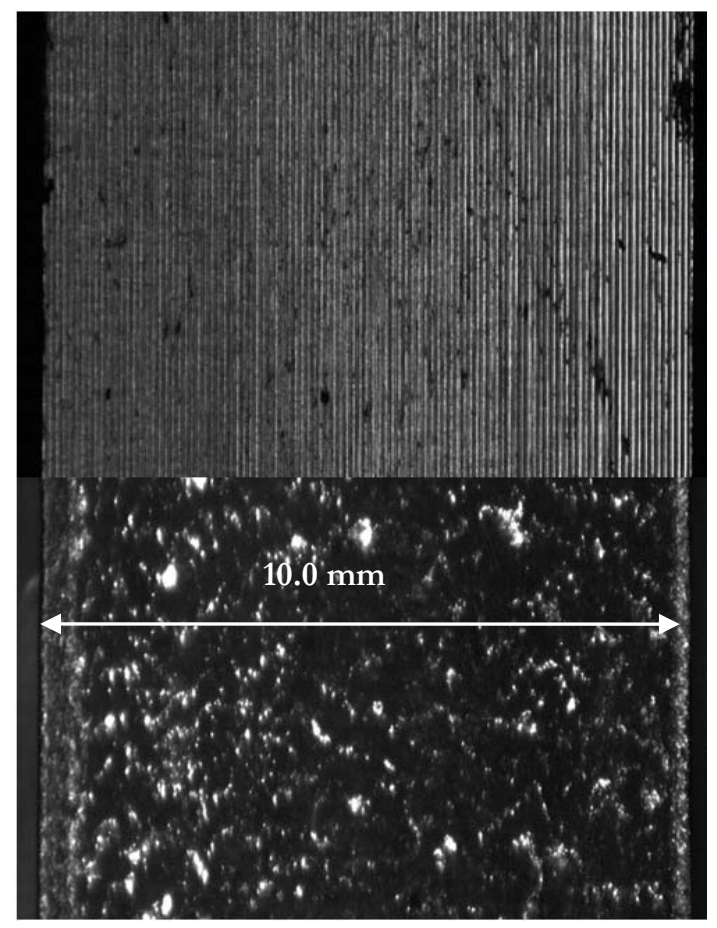

Figure 11. Wheel contact surfaces before (upper) and after (lower) the first 150000 cycles for test B.

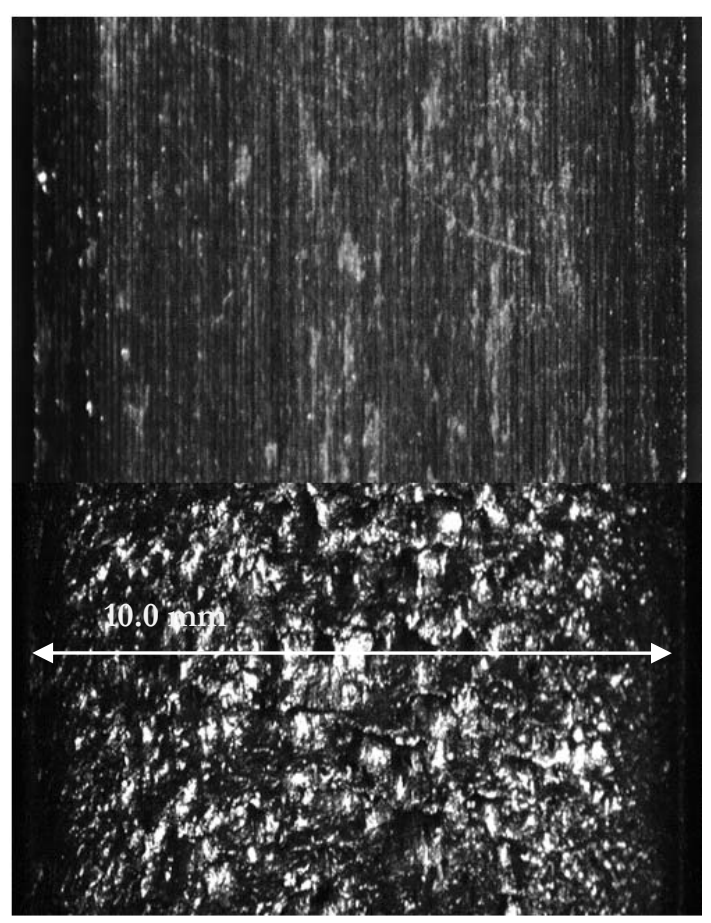

Figure 12. Wheel contact surfaces before (upper) and after (below) the first 200,000 cycles for test $C$.

and then the ratio between damaged and visible area was averaged and multiplied by the nominal thickness of the specimen.

When no clear traces of the original surface of the wheel specimen was identified in the image, the whole surface width $(10.0 \mathrm{~mm})$ was considered as damaged.

\subsection{Micro-hardness}

After the tests were completed, micro-hardness measurements were taken on the cross sections of the cut and polished
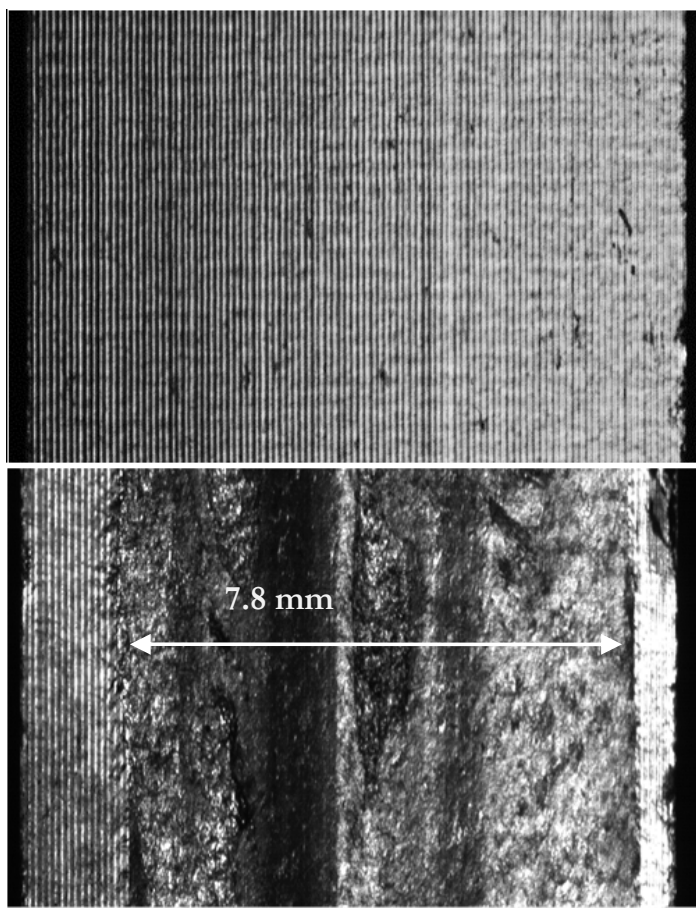

Figure 13. Wheel contact surfaces before (upper) and after (lower) the first 200000 cycles for test $D$.

specimens at different depths. The resulting hardness profiles are shown in Figure 14.

A higher hardening was observed in tests with higher sliding ratios and contact pressures, involving layers between $0.4 \mathrm{~mm}$ to $0.8 \mathrm{~mm}$. This behavior could be associated with isotropic hardening.

\subsection{Scanning electron microscope}

The inspection of specimen sections pointed out that the main damage mechanism, in both rail and wheel steels samples,

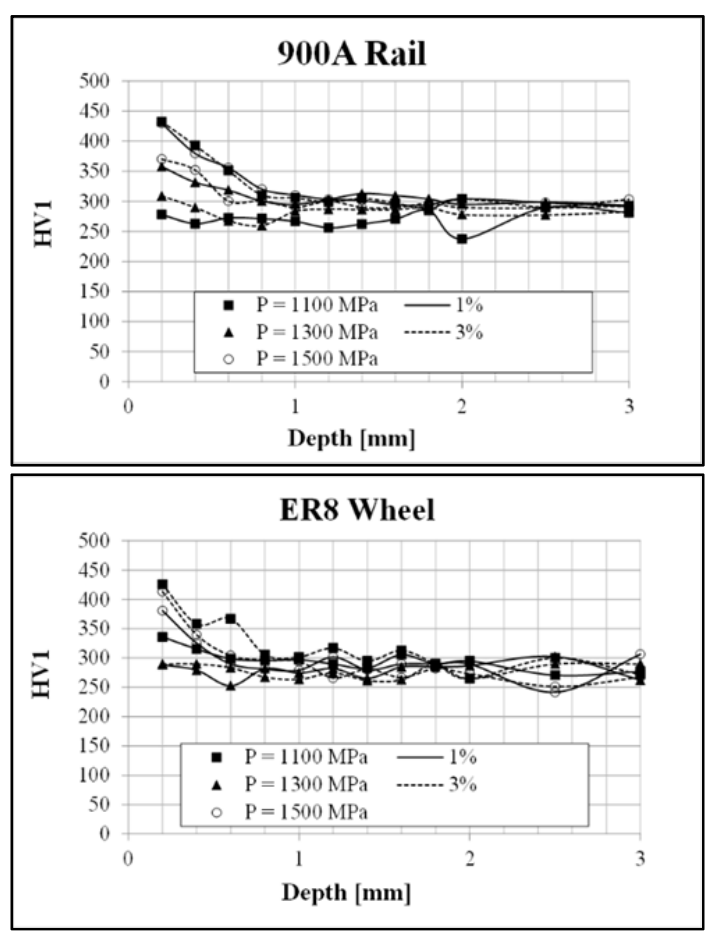

Figure 14. Micro-hardness profiles on the cross-section of rail (upper) and wheel (lower) steel specimen. 
was ratcheting, initiating cracks which propagate to cause RCF failure.

Figure 15 shows the RCF crack path for various test conditions: the rail steel samples ( $a$ and $c$ ) were always less damaged than the wheel steel ones (b and d) in all tested conditions, and presented only surface cracks. In addition, the wheel steel samples also presented subsurface cracks.

All surface and subsurface cracks, which were analyzed, displayed a shallow angle to the surface and follow the plastically deformed material during their growth.

\subsection{Early stage measurements}

To better understand the relationship between the vibrationbased index proposed and wear, in early stages of the damaging process, a separate test has been performed, as indicated in Section 2.2.

While for previous tests a surface image was available only every 200000 cycles, this test was halted every 1500 cycles, and the wheel specimen surface was photographed.

This allowed to identify when the flattening due to wear started, and its progression, using the same procedure described in Section 4.3, to assess the damaged surface width from surface images, such as the ones displayed in Figure 16.

The superposition between the two measurements, up to the first 40000 cycles, is displayed in Figure 17, and shows how the $D_{x / T}$ index and the damaged surface width have a similar

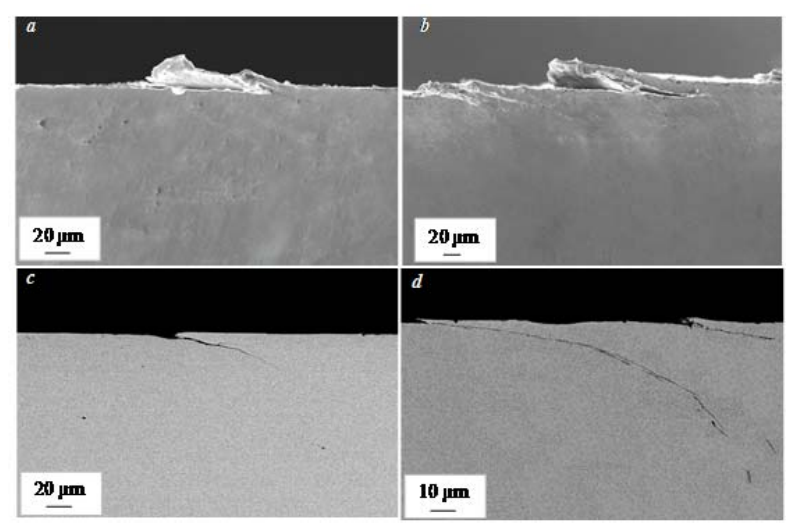

Figure 15. RCF crack path in: a) rail steel sample tested at $s=1 \%$ and $P=1500 \mathrm{MPa}$; b) wheel steel sample tested at $\mathrm{s}=1 \%$ and $P=1500 \mathrm{MPa}$; ) rail steel sample tested at $\mathrm{s}=3 \%$ and $P=1300 \mathrm{MPa}$; $\mathrm{d}$ ) wheel steel sample tested at $\mathrm{s}=3 \%$ and $P=1300 \mathrm{MPa}$.

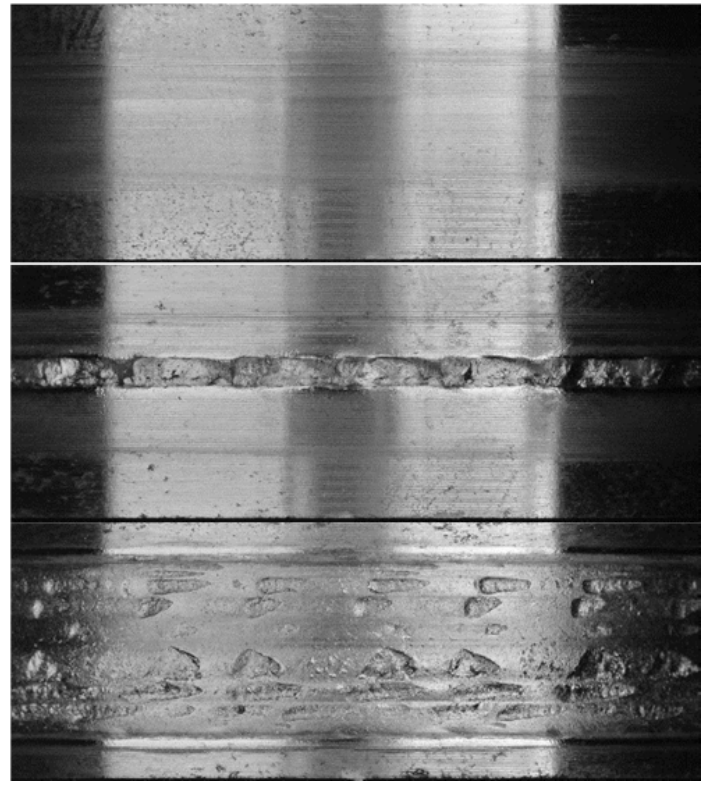

Figure 16. Surface of the wheel specimen in early stage tests after 3000 cycles (upper), 18000 cycles (mid) and 27000 cycles (lower).

behavior. During the first 12000 cycles $D_{x / T}$ is stationary and low $\left(100 \mathrm{~kg}^{-1} \mathrm{~m}^{-1}\right)$, while the wheel surface does not display any damage. Between 13500 and 25500 cycles, $D_{x / T}$ quickly increases up to a high stationary value $\left(300 \mathrm{~kg}^{-1} \mathrm{~m}^{-1}\right)$. In the same period the damaged width rises from $0 \mathrm{~mm}$ to $7.5 \mathrm{~mm}$, indicating a rapid flattening of the surface due to a high wear rate. After 25000 cycles, $D_{x / T}$ displays a stationary behavior, while wear rate decreases to about one third, completing the flattening at 34500 cycles.

\section{DISCUSSION}

The material plastic behavior was simulated using a numerical simulation for rolling contact [12], already calibrated on ER8 EN13262 and UIC 900A74 [13]. The model predicts plasticization in a two-dimensional plane-strain half-space subjected to contact pressure and friction, also taking into account wear as a concurring phenomenon removing layers from the surface.

Input parameters for this model are specimen geometry (radius and contact width), load, friction coefficient, material

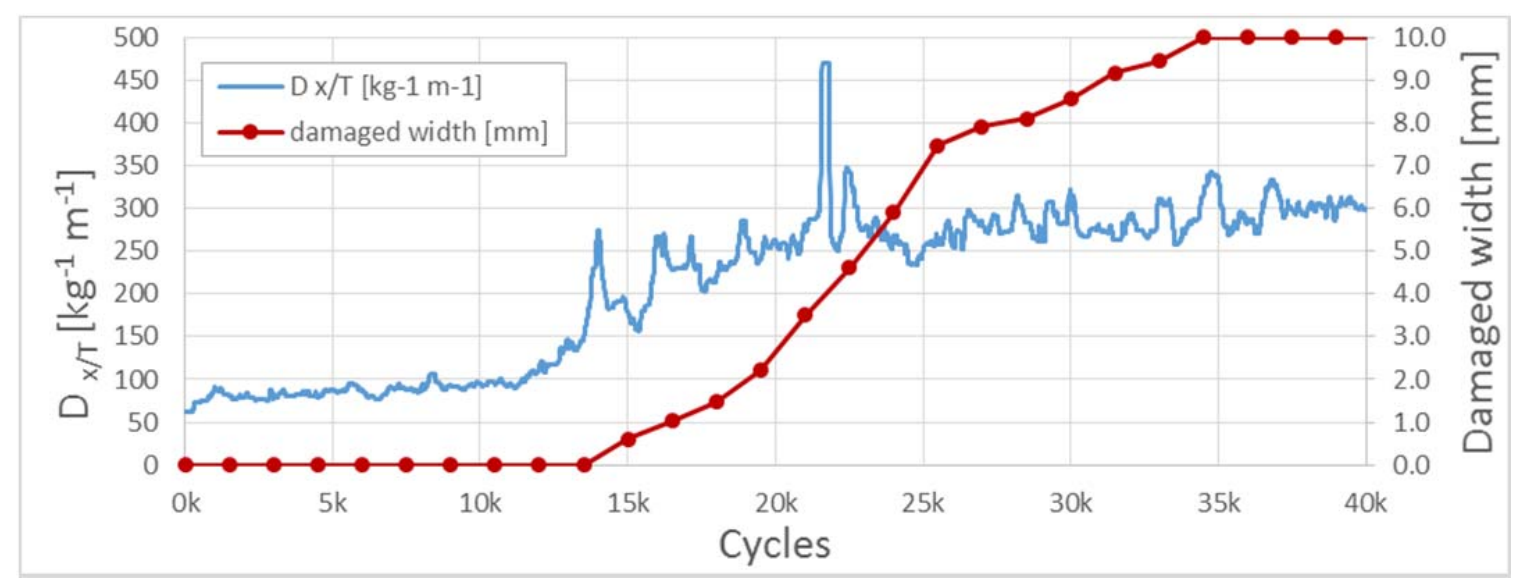

Figure 17. Early stage damage progression: damaged surface width from photographs (red, right axis) and vibration-based $D_{x / T}$ index (blue, left axis). 
properties (yield stress, elastic constants, isotropic and kinematic hardening constants) and wear rate.

The micro-hardness profiles pointed out a behavior associated with isotropic hardening, which allowed for a model simplification, supposing a linear relationship between yield stress and hardness.

The images taken after the first 200000 cycles, displayed in Figure 11 to Figure 13, proved that wear flattened the rail specimen, thus increasing the contact surface and reducing the actual contact pressure exerted.

Vibrations analysis, in particular of the first 20000 cycles, reported in Table 3, identified a time frame in which the flattening process was occurring.

Time and extent of the flattening detected by $D_{x / T}$ allowed to replace the standard point Hertz contact in the model with a line contact surface, with a track width of $10 \mathrm{~mm}(8 \mathrm{~mm}$ for the $1 \%$ sliding ratio), occurring at the very beginning of the RCF simulations, as shown in Table 4.

Figure 18 shows the calculated displacements due to plastic strain in the ER8 specimen in test D $(F=3830 \mathrm{~N}$ and $s=1 \%)$ of material points that before the deformation process were standing along a vertical line.

The simulation allowed predicting that a stationary state was reached in the material strain distribution after 200,000 cycles, coherently with what was experimentally observed in terms of both wear rate and vibration parameters. Figure 19 shows the superposition of the observed subsurface microstructure with curves representing the calculated displacements: these curves are in agreement with the general aspect of the microstructure.

The simulation correctly predicted that the cracks and plasticized layers could not be deeper than $40-50 \mu \mathrm{m}$, even though ratchetting never stops, because wear removes plasticized and cracked layers from the surface, preventing deep crack propagation.

The ex-post analysis of the monitored index $D_{x / T}$ showed good correlation with destructive and non-destructive test

Table 4. Nominal and measured width of specimens as used for simulation.

\begin{tabular}{|c|c|c|c|}
\hline \multirow[t]{2}{*}{ ID } & $\begin{array}{l}\text { Nominal } \\
\text { contact width }\end{array}$ & $\begin{array}{c}\text { Contact width } \\
\text { used }\end{array}$ & $\begin{array}{l}\text { Width } \\
\text { reported since }\end{array}$ \\
\hline & {$[\mathrm{mm}]$} & {$[\mathrm{mm}]$} & [cycles] \\
\hline$A$ & 1.785 & 10 & 4700 \\
\hline$B$ & 2.113 & 10 & 8500 \\
\hline $\mathrm{C}$ & 2.440 & 10 & 12700 \\
\hline$D$ & 2.440 & 8 & 8200 \\
\hline
\end{tabular}

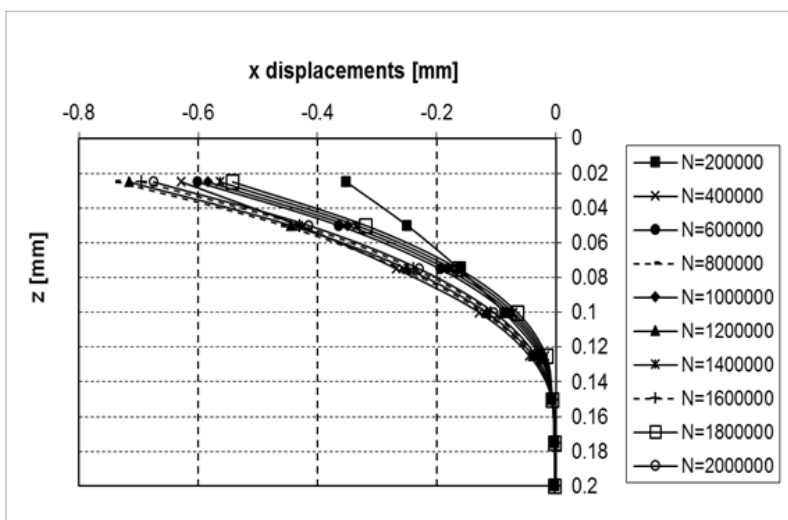

Figure 18. Calculated displacements due to plastic strain in ER8 specimen in test $\mathrm{D}(F=3830 \mathrm{~N}$ and $s=1 \%)$.

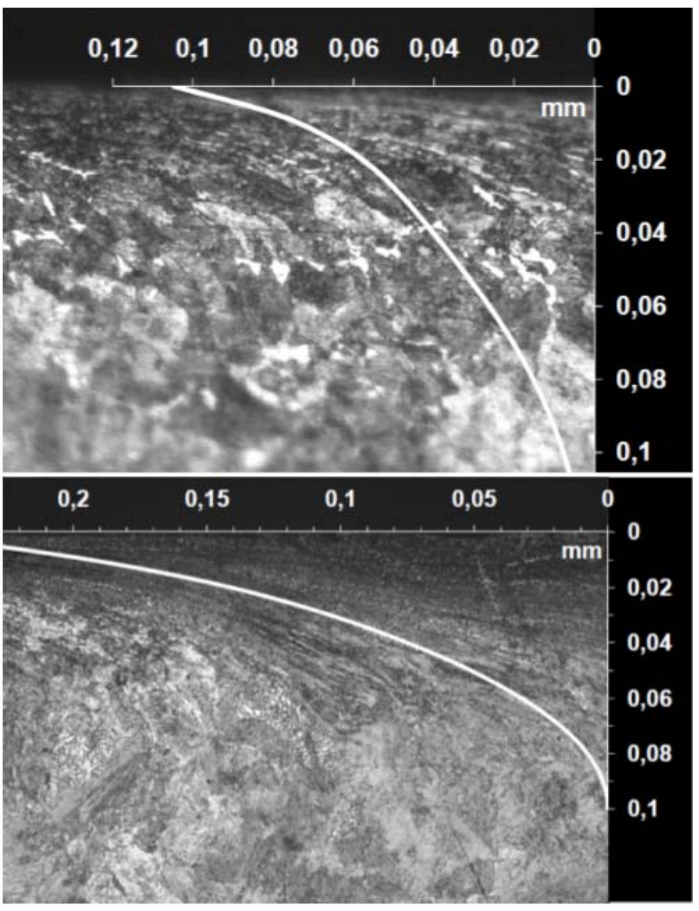

Figure 19. Superposition of calculated (white) and observed (image) plastic strain bands in tests with $\mathrm{s}=1 \%$ and $P=1100 \mathrm{MPa}$ (left), and $\mathrm{s}=1 \%$ and $P=1300 \mathrm{MPa}$ (right), after 2000000 cycles.

result. Nonetheless, its interpretation could still be difficult, due to the fact that the stationary level (for tests A to D about 30 $\mathrm{kg}^{-1} \mathrm{~m}^{-1}$ as seen in Figure 1) is unknown until it is reached. Therefore making deductions, based on the proposed index real time analysis, could still be unfeasible while the test is in its early stage.

Monitoring the proposed index while the test is still running could be feasible after the first 20000 cycles, although for its interpretation to be practical still more work is needed, especially towards producing a smoother and more stable $D_{x / T}$ value for the whole RCF life test duration.

Further tests should be performed, using the same technique on different materials and conditions, to assess the proposed method robustness. Moreover, future studies could focus on making the index more easily computed and assess in real time.

\section{CONCLUSIONS}

A procedure to assess the presence, onset and duration of collaborative RCF and wear phenomena leading to contact shape alteration was proposed. The approach was applied to a wheel and rail steels characterization procedure based both on rolling-sliding contact tests, on disc specimens, and numerical simulation.

An early stage evaluation of the damage process provided evidence that the vibration-based index proposed is able to detect high wear transient states during which the concurring damage phenomena alter the specimen shape.

This allows altering the numerical model used for characterization accordingly, without halting tests and removing the specimens from the test bench. The advantage of the proposed method rests, in fact, in its non-destructive and inline nature, therefore allowing for a continuous assessment without interfering with the specimens.

This procedure completes the described full RCF failure life test, and allows to correct numerical models required to 
characterize the materials. It points out phenomena whose duration is too short to be taken into account by the same numerical model describing, for the whole RCF life of the specimen, the different damage phenomena and their interactions in a complex case as cyclic contact.

\section{ACKNOWLEDGEMENT}

The authors are grateful to Mr. Silvio Bonometti and Mrs. Valentina Ferrari for their support in the experimental activities, and to Prof. Franco Docchio for careful reading and revision.

\section{REFERENCES}

[1] Zerbst U., Beretta S., "Failure and damage tolerance aspects of railway components", Engineering Failure Analysis, 2011, 18 pp. 534-542

[2] Donzella G. et al. "Progressive damage assessment in the nearsurface layer of railway wheel - rail couple under cyclic contact", Wear, 2011, 271(1-2), pp. 408-416

[3] Fedele R., Filippini M., Maier G., "Constitutive model calibration for railway wheel steel through tension-torsion tests", Computers \& Structures, 2005, 83(12-13), pp. 1005-1020.

[4] Liu Y., Stratman B., Mahadevan S., "Fatigue crack initiation life prediction of railroad wheels", International Journal of Fatigue, 2005, 28, pp. 747-756.

[5] Liu Y., Liu L., Mahadevan S., "Analysis of subsurface crack propagation under rolling contact loading in railroad wheels using FEM", Engineering Fracture Mechanics, 2007, 74, pp. 2659-2674.

[6] Solazzi L. et al. "Rolling contact fatigue damage detected by correlation between experimental and numerical analyses", Structural Durability and Health Monitoring, 2012 8(4), pp. 329340

[7] Mahfoud, J., Breneur, C.., "Experimental identification of multiple faults in rotating machines", Smart Structures and Systems, 2008, 4(4), pp. 429-438.

[8] Byington, C.S., et al., "Shaft coupling model-based prognostics enhanced by vibration diagnostics", Insight: Non-Destructive Testing and Condition Monitoring, 2009, 51(8), pp. 420-425.

[9] Roemer, M.J., C.S. Byington, and J. Sheldon, "Advanced vibration analysis to support prognosis of rotating machinery components", International Journal of COMADEM, 2008, 11(2), pp. 2-11.

[10] Borghesani, P., Pennacchi, P., Randall, R. B., Sawalhi, N., and Ricci, R., 2013, "Application of cepstrum pre-whitening for the diagnosis of bearing faults under variable speed conditions", Mechanical Systems and Signal Processing, 36(2), pp. 370-384.

[11] Solazzi, L., C. Petrogalli, and M. Lancini, "Vibration based diagnostics on rolling contact fatigue test bench", Procedia Engineering 2011, 10, pp. 3465-3470.

[12] Mazzù A., "Surface plastic strain in contact problems; prediction by a simplified non-linear kinematic hardening model", Journal of Strain Analysis, 2009, 44(3), pp. 187-199.

[13] Mazzù A., et al. "An integrated model for competitive damage mechanisms assessment in railway wheel steels", Wear 322-323, 2015, pp. 181-191. 